\title{
The Analysis of Badminton Referee Performance
}

\author{
Ari Subarkah*, Ika Novitaria Marani, Rizky Fauzi Akbar \\ Fakultas Ilmu Olahraga \\ Universitas Negeri Jakarta \\ Jakarta, Indonesia \\ *arisubarkah@unj.ac.id
}

\begin{abstract}
In every badminton match, athletes will compete to be the best in a sport by taking into account the norms or rules that apply in the match. And the one who can set and run the rules of the game is the referee. The presence of the referee in a match is very important, because the referee is the spearhead for the success of the match. Therefore, this research was conducted with the aim to determine the performance of badminton referees in the Badminton National Championship match in Jakarta. The samples involved in this study were 13 referees who led the team competition at the National Championship in Jakarta. The results related to the performance of the referee showed that they had very good results in matches with high difficulty. It was indicated by the average value obtained $(9.1)$. It shows that a referee must be equipped with knowledge about the rules of the game in force, have a clear voice, and have a firm attitude.
\end{abstract}

\section{Keywords: badminton, referee performance}

\section{INTRODUCTION}

Based on the explanation above, it can be said that the task of a referee must be able to make effective decisions. Because effective decision making is a key component of performance in games for athletes [1]. Errors in decisions made by the referee when leading will damage the game. Not just tarnishing the match sometimes in a match if the referee makes a mistake there will be some reaction from various groups both players, line judges, coaches, officials and supporters. So that will trigger the emergence of aggressive actions from players or spectators. This is supported by Fruchart which states that the decision making mistakes or unethical decisions made by referees make it possible to make the game more rough and show observers about their ability to control the match [2]. Therefore, an understanding of the rules held by the referee can make the match go well as expected and provide satisfaction for players who compete, namely victory. This is supported by Donahue which states that passionate athletes may be so involved in their sport that they are likely to be aggressive if victory is on the line. And an understanding of the rules held by the referees can help them make the right decision [3].

The frequency of right and wrong decisions made in sports is called performance decision making. According to Corringan, decision making is influenced by a complex mix of physical, social, psychological and environmental factors. And there is a fundamental difference between the player and the referee in the decision making process, namely the referee's decision only includes the identification of violations of the rules according to the laws of the game and does not include executing playing skills [4]. Research on decision making was also carried out by Catteeuw which showed the results that referees have a common goal, namely to apply the rules of the game that apply uniformly and consistently [5]. To be able to apply uniform and consistent rules of the game requires decision-making skills. So, the research recommends making the referees' decision-making skills training program outside the competition.

However, previous studies have not discussed much about the performance of referees in individual game sports such as badminton. In addition, there are not many studies conducted that discuss the decision made when the referee leads the match. Moreover, badminton is one sport that has experienced several changes to the rules of the game. With this change in regulation, it is necessary to conduct research on how the referee's performance is seen in every decision made when leading the match. Therefore, researchers are interested in conducting research on the performance of badminton referees when leading a match. The purpose of this study is to provide a qualitative picture, especially for badminton organizations in the field of referees, how the performance of badminton referees has been leading the badminton competition.

\section{Research Methodology}

\section{A. Data Analysis Method and Technique}

The research method used in this research is descriptive method. The research data taken was then analysed to be able to give an idea of how the rules of the referees' game were judged by how they were currently leading the badminton competition at the national championship in Jakarta. The data analysis technique used is descriptive statistics relating to the application of statistical methods to collect, process, present and analyse quantitative data so as to provide an explanation of the results of research related to the performance of Indonesian national badminton referees.

\section{B. Subjects}

This research was conducted at the sports club of the Faculty of Sports, Jakarta State University. The population in this study was the National referee of Indonesia (PB. PBSI) who led in the 2018 National Championship. Total referee who led the national championship were 40 referees. The Referee who can lead the match at the National Championship must have a national license. The research sample used as many as 13 referees using purposive sampling techniques. The 


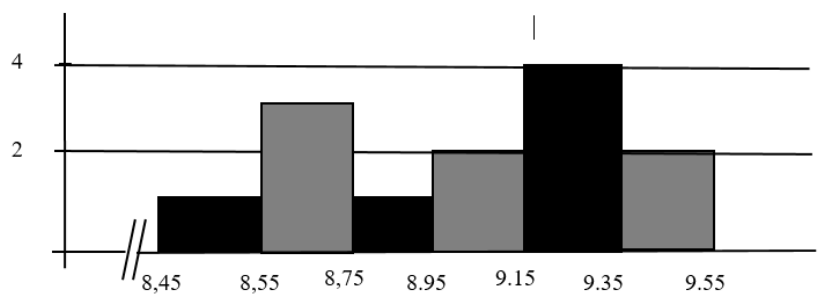

Fig. 1. Histogram tendency of referee performance.

The following is the description data for each round of matches starting from the semi-finals and finals. The Semi Final Round is described in two parts, namely the semi-final round I and the semi-final round II. The data description per round is as follows:

1) Semifinal I: Following is a description of the descriptive data and frequency distribution of the referee's performance in the semifinal I match:

TABLE III. DESCRIPTION OF REFEREE PERFORMANCE SEMIFINAL I

\begin{tabular}{|l|l|}
\hline \multicolumn{1}{|c|}{ Description } & \multicolumn{1}{c|}{ score } \\
\hline Median & 9.2 \\
\hline Modus & 9.3 \\
\hline Mean & 9.1 \\
\hline Standard Deviation & 0.24 \\
\hline Maximum & 9.3 \\
\hline Minimum & 8.8 \\
\hline
\end{tabular}

TABLE IV. Frequency Distribution OF REFEREE PERFORMANCE SEMIFINAL I

\begin{tabular}{|l|l|l|}
\hline \multicolumn{1}{|c|}{ No } & \multicolumn{1}{|c|}{ Score } & \multicolumn{1}{c|}{ Frequency } \\
\hline 1 & 8,8 & 1 \\
\hline 2 & 9,1 & 1 \\
\hline 3 & 9,3 & 2 \\
\hline \multicolumn{2}{|l}{} & 4 \\
\hline
\end{tabular}

Furthermore, the tendency of the semifinal I performance referee frequency distribution above is illustrated in the histogram diagram as illustrated in diagram 2 below.

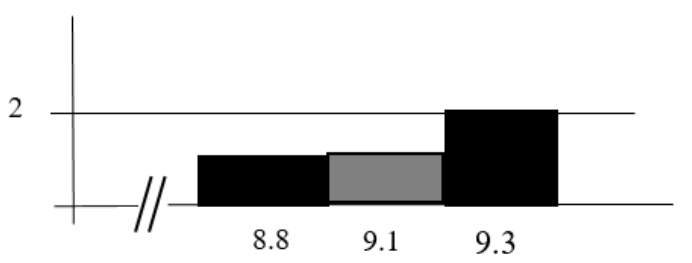

Fig. 2. Histogram tendency of referee performance semifinal I.

2) Semifinal II: Following is a description of the descriptive data and frequency distribution of the referee's performance in the semifinal II match: 
Furthermore, the tendency of Final round performance referee frequency distribution above is illustrated in the histogram diagram as illustrated in diagram 4 below.

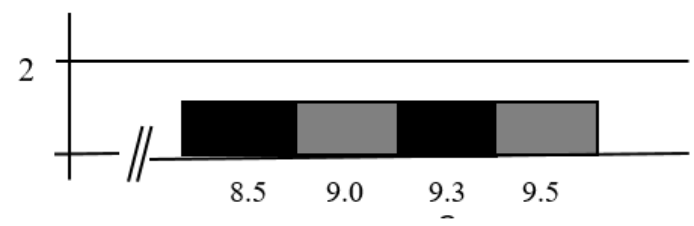

Fig. 4. Histogram tendency of referee performance final round

\section{DISCUSSION}

Referee performance implementation data is taken from senior team matches from the Semi-Final and Final. The total matches that occurred during the Semi Final and Final were 13 matches. This is because in the semi-final and final matches there is no match for all match numbers. One of the Semi Final matches that does not compete with all numbers is Djarum against Mutiara with a score of $3-1$. Whereas for the Final only matches 4 (four) numbers. Because the winner, Jaya Raya, had obtained a score of 3 (three) beforehand from his opponent, namely Mutiara.

Referee performance evaluation is done when the referee leads the match. As for what is assessed from the referee's performance is field control and cooperation. The results of the referee's performance assessment have three criteria by also looking at the level of difficulty of the match itself. The three criteria are very good, good and very bad. Very good results are obtained if the referee who leads the match can explain and respond to incidents that are considered to affect the course of the match, such as when a player slows the tempo of the game, then the referee must reprimand him and others. While bad results are obtained if the referee who leads the match cannot explain and respond to incidents that affect the course of the match, such as slowing down the game, then the referee leaves it until the player does it repeatedly and others.

In addition, the difficulty factor of the match was also seen from the match which brought together players who were ranked almost the same at both the national and world level. Besides having the same rank, the player is also a player who dropped in the International championships. So, of course this has an impact on the experience of the players in playing and how they deal with the rules of the match.

The results of the referee's performance during the Semifinal I, Semifinal II and Final stages showed that the implementation of the referee's performance when leading the match was very good in matches with high difficulty, both for field control and in terms of cooperation. This is because the referee who leads the match is able to explain and respond to incidents that affect the course of the match and the players who meet have almost the same rankings both nationally and internationally. In addition, these players also often go down in the international championship event. However, there are some notes that must be corrected by the referees who lead in this championship, namely: 
- When introducing a player, reduce the pauses and slightly speed up the delivery method.

- When starting a match, the pronunciation should be harder and clearer when introducing players.

- Before starting the match, the referee should ensure that there are no things that interfere with the game.

Based on the discussion above, it can be said that a referee has a great responsibility in managing the competition and one that must be obeyed by the referee is fair or impartial. Appropriate decision making is considered the role of the most important referee in the match, because the referee ensures that the match is played in a fair and safe manner while maintaining the integrity of the game [6]. Thus, a badminton referee must know and fully understand all the rules of badminton games, tournament regulations, codes of conduct and duties in accordance with the rules made by BWF.

The purpose of using decision making has a positive and direct impact on the outcome of the competition. And to be able to make good decisions, a referee must have cognitive perception [7]. That is what makes the difference between skilled and less skilled referees lies in perception skills at the time of decision making [8]. Perceptual-cognitive expertise refers to the ability of performers to identify and process (environmental) information for integration with existing knowledge to facilitate the selection of appropriate responses under time pressure $[9,10]$.

Every referee has a strong desire to run rules and regulations that are free from mistakes. Because referees are given the task of implementing game laws and ensuring that players comply with regulations [11]. Erroneous decisions taken by referees can make players act aggressively because they consider referees' decisions unfair [12]. Therefore, to improve the quality of badminton ranging from regional, national to world, it requires qualified and professional referees to lead a match. The referee is said to be professional can be seen through mastering the rules of the game well, having good conditions, having and mentally in leading a match. A good referee must have good concentration and accuracy because the referee could be an enemy to the player if in the match is not concentrated or inaccurate. The researcher suggests to conduct further research related to the analysis of the time span of problem solving required by the referee or how the emotion of the referee when resolving the problem that occurs.

\section{CONCLUSION}

Based on the research results obtained, it can be concluded that the decision of the referee has very good results in matches with high difficulty. This is indicated by the average value obtained which is 9.1. The grading points that are judged are the field control and cooperation considered to have been done very well by the referee when leading the match. However, there are still some notes that must be repaired by the badminton referee who is leading the match. So, it is expected that PBSI will schedule referees regularly and continuously. And other researchers are expected to be able to conduct research on referees, which can still be studied in more depth.

\section{REFFERENCES}

[1] J.F. Gréhaigne, P. Godbout, D. Bouthier, "The Teaching and Learning of Decision Making in Team Sports," Quest, vol. 53, pp. 59-76 2001.

[2] E. Fruchart, A.Carton, "How do amateur soccer referees destabilize a match?," Psicologica, vol. 33, pp. 435-449, 2012.

[3] E.G. Donahue, B. Rip, R.J. Vallerand, "When winning is everything: On passion, identity, and aggression in sport," Psychol Sport Exerc, vol. 10, pp. 526-534, 2009.

[4] S.L. Corrigan, D.B. Dwyer, B. Harvey, et al, "The influence of match characteristics and experience on decision-making performance in AFL umpires," J Sci Med Sport, vol. 22, pp. 112-116, 2019.

[5] P. Catteeuw, W. Helsen, B. Gilis, et al, "Decision-making skills, role specificity, and deliberate practice in association football refereeing," $\mathrm{j}$ sports sci, vol. 27, pp. 1125-1136, 2009.

[6] N. Elsworthy, D. Burke, B.J. Dascombe, "Factors relating to the decision-making performance of Australian football officials," Int J Perform Anal Sport, vol. 14, pp. 401-410, 2014.

[7] D.J. Hancock, D.M. Ste-Marie, "Gaze behaviors and decision making accuracy of higher- and lower-level ice hockey referees," Psychol Sport Exerc, vol. 14, pp. 66-71, 2013.

[8] P. Larkin, J. Berry, B. Dawson, et al, "Perceptual and decision-making skills of Australian football umpires," Int J Perform Anal Sport, vol. 11, pp. 427-437, 2011.

[9] J. Spitz, K. Put, J. Wagemans, et al, "The role of domain-generic and domain-specific perceptual-cognitive skills in association football referees," Psychol Sport Exerc, vol. 34, pp. 47-56. 2018.

[10] D.T. Mann, A.M. Williams, P. Ward, and C.M. Janelle, "Perceptualcognitive expertise in sport: A meta-analysis," Journal of Sport and Exercise Psychology, vol. 29(4), pp. 457-478, 2007.

[11] P. Dawson and S. Dobson, "The influence of social pressure and nationality on individual decisions: Evidence from the behaviour of referees," Journal of Economic Psychology, vol. 31(2), pp.181-191, 2010.

[12] E. Reynes, S. Canovas, C. Ferrand, and N. Pantaleon, "Emotional consequences of referee's mistake among soccer players: exploratory study," Psicologia \& Sociedade, vol. 20(1), pp.5-15, 2008. 